\title{
ArcheoSciences
}

Revue d'archéométrie

33 (suppl.) | 2009

Mémoire du sol, espace des hommes

\section{Contribution of geophysical methods to explaining water flow in a carbonate medium Favray site (Nièvre, France)}

Mohammad Hamidi, Asal Sirhan and Pierre Andrieux

\section{OpenEdition}

Journals

Electronic version

URL: https://journals.openedition.org/archeosciences/1550

DOI: 10.4000/archeosciences. 1550

ISBN: 978-2-7535-1599-4

ISSN: $2104-3728$

Publisher

Presses universitaires de Rennes

\section{Printed version}

Date of publication: 30 October 2009

Number of pages: $183-185$

ISBN: 978-2-7535-0943-6

ISSN: $1960-1360$

Electronic reference

Mohammad Hamidi, Asal Sirhan and Pierre Andrieux, "Contribution of geophysical methods to explaining water flow in a carbonate medium Favray site (Nièvre, France)", ArcheoSciences [Online], 33 (suppl.) | 2009, Online since 30 October 2011, connection on 21 September 2021. URL: http:// journals.openedition.org/archeosciences/1550 ; DOI: https://doi.org/10.4000/archeosciences. 1550 


\title{
Contribution of geophysical methods to explaining water flow in a carbonate medium Favray site (Nièvre, France)
}

\author{
Mohammad Hamidi ${ }^{*}$, Asal Sirhan ${ }^{*, * *}$ and Pierre Andrieux ${ }^{* *}$
}

Key words: aquifer, electrical resistivity tomography, heterogeneity, France

\section{QUESTION}

The geologic formations of the study area, limestone and chalky limestone belong to upper Oxfordian and lower Kimeridgian .Two springs; Fontbout $(70$ l/s) and Favray $(300 \mathrm{l} / \mathrm{s})$ are situated in this area. Those two springs are witness to the existence of a water reservoir of important volume. The similarity of the results of their hydro-chemical analysis shows that they belong to the same aquifer.

The direction of water flow in the studied area is NW-SE, the springs are located in the southeast and several wells have been dug in the same area: While some of them are productive, others are dry, although they are close to one another. The aims of study are to explain the reasons why one of the two springs is dry during the dry period while the other is not, although both belong to the same aquifer, and also to identify the geological environment in which some existing wells are productive and others are non- or half-productive by using a geophysical parameter, electrical resistivity. Three different geophysical techniques have been used in a complementary way in order to:

- Locate the impermeable substratum.
- Define the geometry of the structure responsible for the issue of the two springs.

- Determine the nature of principal facies which could influence regional hydrogeological phenomena.

\section{MeTHODS}

A very low frequency (VLF) resistivity map was achieved first; it gave us the first synthesis by giving detailed indications of fractured zones which feed separately the two springs. The results were corroborated by 10 Wenner electrical profiles.

A second synthesis of the vertical structure was performed with the help of ERT (electrical resistivity tomography) and VES (vertical electrical sounding), in fact 85 Schlumberger VES and 2 tomographies. It gave detailed indications of the heterogeneity of the different geological formations, especially the one which we consider its lower part as the substratum with high resistivity (400-1200 ohm.m), and the upper part as the aquifer with low resistivity (80-120 ohm.m). These results were obtained by a geo-electrical calibration using five of the existing wells situated in the studied

* Franco-Palestinian Interdisciplinary Studies Centre (Al-Quds University, Jerusalem, Palestine).

** Department of Applied Geophysics (UMR Sisyphe 7619), University Pierre and Marie Curie (Paris 6), Paris, France. 
area: a well in the northwestern part, two wells in the south and two wells in the east.

\section{Results AND Discussion}

The contour map of VLF resistivity gave a first synthesis of lateral variations with:

- a network of fractures masked by the cultivated horizon, feeding the area of the springs on the studied site.

-horizontal heterogeneity in the same aquifer, revealing the importance of the scale effect in geophysical prospection.

The vertical structure, determined with the help of VES and ERT, gave detailed indications of:

- tectonic and lithologic structure of the stratigraphic series (establishment of a synthetic log and calibration of the vertical resistivity variation);

- vertical lithologic heterogeneity inside the geological formation playing the role of principal aquifer.

A synthesis of previous results shows that the functioning of the studied aquifer can be explained by the existence of a natural barrage opposite to regional flow. This hypothesis was verified by sounding techniques.

The VES results in figure 1 present first the anisotropy of aquifer formation and secondly, seasonal variation. This study of anisotropy shows that aquifer formation owns a low apparent resistivity toward the source and agrees with the regional hydro-geological water flow from NW to SE, where the source is situated. Apparent resistivities in the perpendicular direction are higher. The seasonal study illustrates that the aquifer is divided into two layers; low apparent resistivity above higher apparent resistivity. The thickness of the upper geo-electrical layer changes depending on the seasons, i.e., the water bearing horizon increases in autumn and decreases in summer. Note that the thickness of the substratum (high apparent resistivity) does not change.

- Figure 2 demonstrates the existence of the substratum layer (NE-SW) behind the outcoming spring opposite to the direction of water flow (NW-SE).

- Figure 3 shows that the spring exists in a conductor horizon. This spring is located above a resistant substratum.
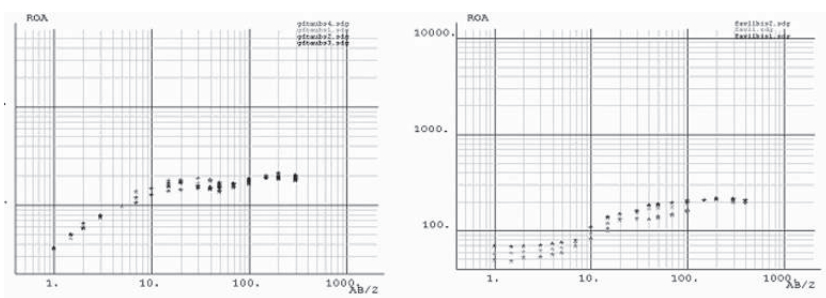

Figure 1: Anisotropy and seasonal measurements.

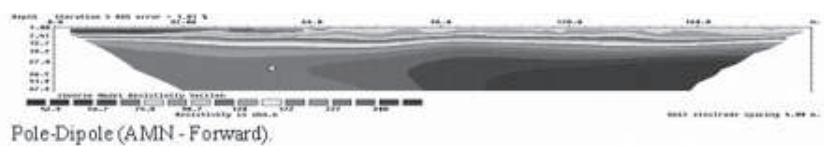

Pole.Dipole (AMN-Forward).

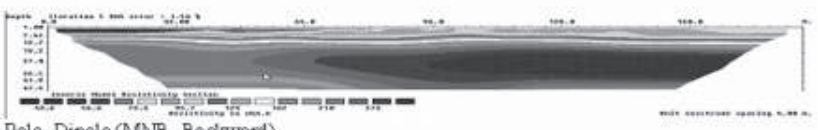

Pole-Dipole (MNB - Backword)

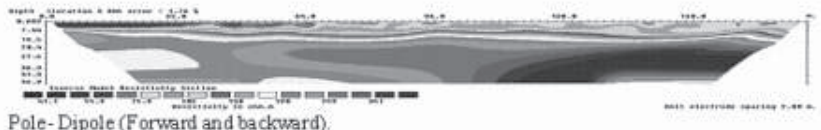

Pole-Dipole (Forward and backward)

Figure 2: Electrical resistivity tomography.

- The obtained results using electrical resistivity tomography are satisfactorily correlated with the results of the electrical sounding and VLF methods.

\section{Conclusion}

The interpretation of electrical soundings showed that there exists a vertical and horizontal change in the geological formation which supplies the five wells located in the studied zone. This geological formation, which is called 'before reef', presents a low apparent resistivity to a depth of about $20 \mathrm{~m}$, and corresponds to chalky and bioclastic high porosity limestone; below this, it starts to become more resistant, forming a base which is micritic and sub lithographic.

We conclude that Favray spring which is not influenced by dry periods is situated at the interface of this change of facies and is fed by the NW-SE regional water flow, although the slope of the geological layers is the NW direction. The fact that Favray spring is not influenced by dry periods is due to the triple nature of its feeding: (1) a net of fractures in connection with the spring, (2) the above mentioned change of facies (chalky and bioclastic low resistivity above the denser and less permeable sublithographic), and (3) an easy water flow from the NW towards the spring situated in the SE part corresponding to lower resistivity anisotropy.

Fontbout spring is situated in the resistive part of the aquifer (substratum) and is fed only by local overlying fractures, which are mostly influenced by seasonal rainfall.

The barrier corresponds to an outcrop resistive reef.

The study has provided a model of water flow and proven the existence of barrage. The model could be used as a reference to be applied in other regions with comparable components (water flow different from the slope of the layers and heterogeneity of the layers with lateral and vertical changes). 


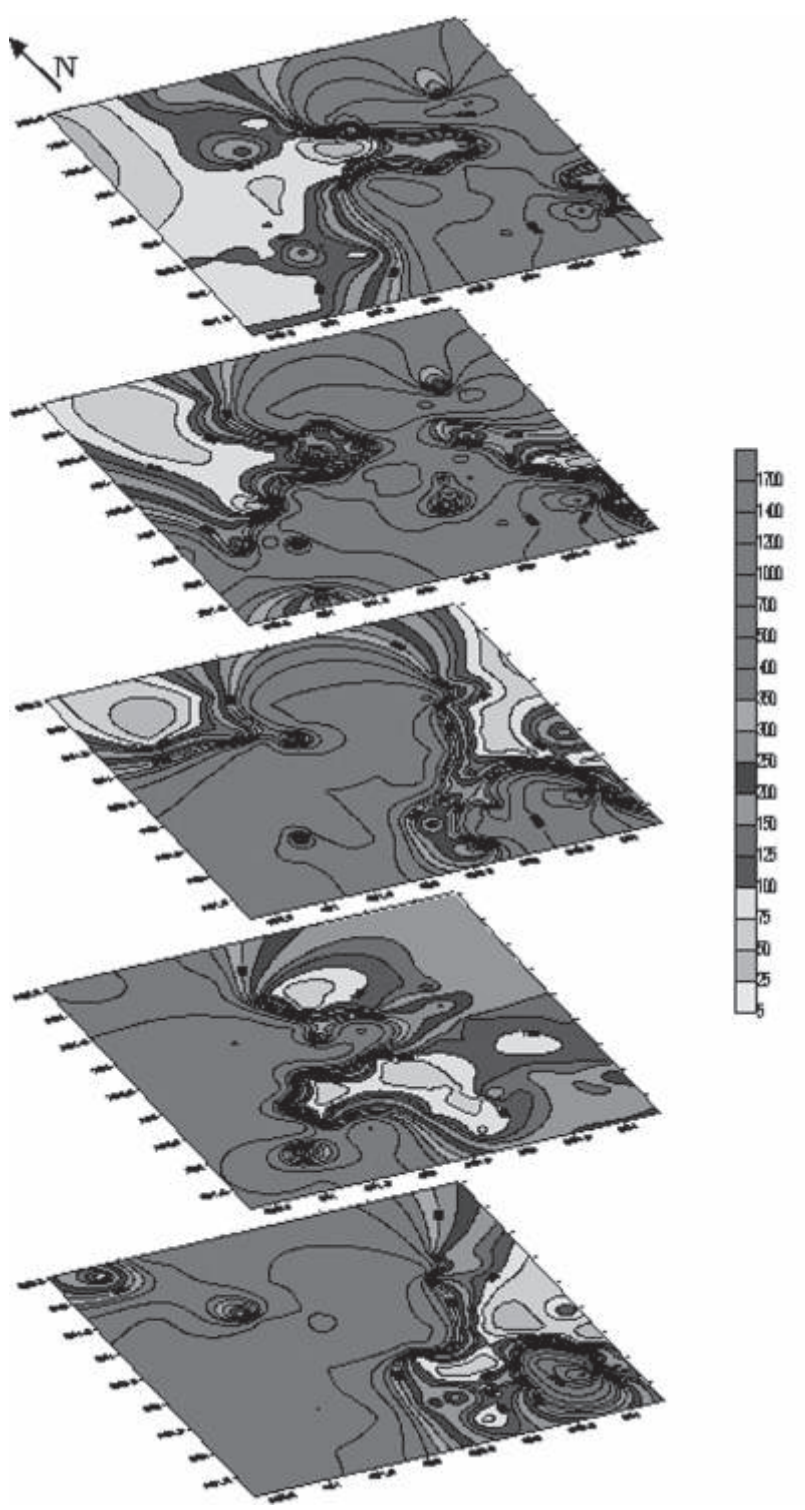

\section{Acknowledgments}

We would like to thank the Head, Department of Applied Geophysics, University of Pierre and Marie Curie, for providing the materials.

Figure 3: Electrical resistivity images at 40,50,60,70 and 90 metres. 